\title{
A protocol of scoping review of peak point prediction methods for epidemic diseases: Applicable to coronavirus 2019 prediction
}

\author{
Elham Nazari1 ${ }^{(1)}$, Zahra Ebnehoseini² ${ }^{2}$, Hamed Tabesh ${ }^{3 *(i)}$ \\ ${ }^{1}$ Ph.D. Student of Medical Informatics, Department of Medical Informatics, Faculty of Medicine, Mashhad University of Medical Sciences, \\ Mashhad, Iran \\ ${ }^{2}$ Ph.D. in Medical Informatics, Psychiatry and Behavioral Sciences Research Center, Mashhad University of Medical Sciences, Mashhad, Iran \\ ${ }^{3}$ Assistant Professor, Department of Medical Informatics, Faculty of Medicine, Mashhad University of Medical Sciences, Mashhad, Iran
}

\begin{tabular}{|c|c|}
\hline Article Info & A B S T R A C T \\
\hline $\begin{array}{l}\text { Article type: } \\
\text { Review }\end{array}$ & \multirow{2}{*}{$\begin{array}{l}\text { Introduction: Given, widespread COVID-19 across the world a } \\
\text { comprehensive literature review can be used to forecast COVID-19 peak in } \\
\text { the countries. The present protocol study aimed to explore epidemic peak } \\
\text { prediction models in communicable diseases. }\end{array}$} \\
\hline Article History: & \\
\hline $\begin{array}{l}\text { Received: 2021-01-26 } \\
\text { Accepted: 2021-04-08 } \\
\text { Published: } 2021-04-10\end{array}$ & \multirow{3}{*}{$\begin{array}{l}\text { Material and Methods: This protocol study was conducted based on } \\
\text { Arksey and O'Malley's. This framework encompasses purpose and } \\
\text { hypothesis, modeling, model achievements aspects. A systematic search of } \\
\text { English in PubMed was conducted to identify relevant studies. In the pilot } \\
\text { step, two reviewers independently extracted the variables from } 10 \text { eligible } \\
\text { studies to develop a primary list of variables and a data extraction form. In } \\
\text { the second step, all eligible studies were assessed by researchers. In the third } \\
\text { step, two data extraction forms were combined. The data were extracted and } \\
\text { categories were created based on frequency. Qualitative and quantitative } \\
\text { methods were used to synthesize the extracted data. }\end{array}$} \\
\hline $\begin{array}{l}\text { *Correspondin } \\
\text { Hamed Tabesh }\end{array}$ & \\
\hline $\begin{array}{l}\text { Assistant Professor, Department of } \\
\text { Medical Informatics, Faculty of } \\
\text { Medicine, Mashhad University of } \\
\text { Medical Sciences, Mashhad, Iran }\end{array}$ & \\
\hline Email:TabeshH@mums.ac.ir & \multirow{2}{*}{$\begin{array}{l}\text { Results: The current study were focused on forecasting the epidemic peak } \\
\text { time that is a worlds' concern issue. The results of current scoping review on } \\
\text { prediction methods for epidemic disease can provide foundational } \\
\text { knowledge, and have important value for the prediction model studies of } \\
\text { COVID-19. }\end{array}$} \\
\hline $\begin{array}{l}\text { Keywords: } \\
\text { Forecasting } \\
\text { Prediction } \\
\text { Peak }\end{array}$ & \\
\hline Epidemic Diseases & $\begin{array}{l}\text { Conclusion: Our findings will help researchers by a summary of evidence to } \\
\text { present new ideas and further research especially for studies were focused } \\
\text { on COVID-19. Our results can improve the understanding of prediction } \\
\text { methods for COVID-19. }\end{array}$ \\
\hline
\end{tabular}

Cite this paper as:

Nazari E, Ebnehoseini Z, Tabesh H. A Protocol of Scoping Review of Peak Point Prediction Methods for Epidemic Diseases: Applicable to Coronavirus 2019 Prediction. Front Health Inform. 2021; 10: 71. DOI: 10.30699/fhi.v10i1.275

\section{INTRODUCTION}

Epidemic refers to "an increase, often sudden, in the number of cases of a particular disease in a community or region during a given period" $[\underline{1}, \underline{2}]$. Today epidemics can transmit speedily across the world. For example, plague, influenza, Ebola, and the Zika virus suddenly speared over several countries and affecting a large number of people. Coronavirus disease (COVID-19) is a newly emerging zoonotic agent that appeared in December 2019 in China [1].

During epidemic diseases the quality of healthcare delivery decrease and morbidity and mortality increase []․ As well, accessibility to health care services dramatically reduce [4] and many organizations face with insufficient resources and monitoring services []․ Given, the epidemic of a specific disease or disease with similar transmission may have happened in similar locations, therefore related information about disease behavior may be identified from the analysis of past outbreaks $[\underline{6}, \underline{7}]$. So, accurate forecasting models to predict the occurrence of epidemic diseases are useful strategies. The results of forecasting models can help policy makers in managing health resources and providing information for decision making. Informed decisions will lead to reduce mortality rate and to improve disease control in epidemics []․ The prediction models of the epidemic peak are example of these models. An epidemic peak prediction model with low error can predict outbreak time for the complex disease [ $\underline{9}-11]$. The various models were used in the 
studies to forecast an epidemic peak. These models provide valuable information about epidemic peak including the time of occurrence, Mont Carlo, ensemble, Incidence Decay and Exponential

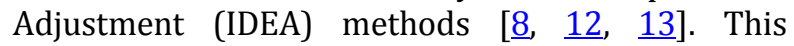
information may be used to improve disease monitoring, provide early warning systems, and efficiently target preventative measures to reduce the impact of diseases [14]. As well, identified epidemic patterns can be used to forecast other infectious diseases [15].

Given, widespread COVID-19 across the world a comprehensive literature review about epidemic peak models is very vital and it can be used to forecast COVID-19 peak in the countries. As far as we know, no systematic identification of epidemic peak prediction models has been conducted. As well, no study has been performed to determine applied prediction models, sources of data gathering, the type of diseases, etc. The aim of present protocol study is to explore epidemic peak prediction models in communicable diseases.

\section{MATERIAL AND METHODS}

The scoping review was an evidence-based article that answered a range of research questions and provides directions for future research for advance healthcare practice, policy, and research. This valuable study faces challenges such as variability and lack of consensus in scoping review terminology, definition, methodological conduct, and reporting. This protocol study was conducted based on Arksey and O'Malley's framework that is one of the main methodological and commonly frameworks to design a scoping review [16]. As well, the recommendations of Arksey and O'Malley's framework and Levac et al. enhancement were adopted to clarify each stage [17]. The Arksey and O'Malley framework consists of 5 main stages and an optional stage that are as follows:

Stage 1 . The identification of a research question,

Stage 2. The identification of studies relevant to the research question,

Stage 3. A selection of studies for inclusion in its review,

Stage 4 . The charting of information and data within the included studies

Stage 5. Collecting, summarizing and reporting the results, and

Stage 6. Consultation [optional] [16]. This stage provides opportunities for the client and the involved stakeholders to offer additional references and to go beyond literature $[16,17]$. Stage 6 was not used in the current study.

The Preferred Reporting Items for Systematic Reviews and Meta-Analyses (PRISMA) checklist and the PRISMA 2009 flow diagram will be applied as instrument for designing, reviewing and reporting current scoping review.

\section{Stage 1: Identifying the research question}

There are wide-ranging questions in scoping review, because this type of study emphasizes the summary of evidence in all its aspects. The main aspects for defining the questions were defined initially which were listed in Table 1.

Table1: Research questions

\begin{tabular}{|l|l|}
\hline Aspect & Questions \\
\hline \multirow{5}{*}{ General } & When the studies were \\
published (publication \\
year)? \\
What was the discipline of \\
the authors of the studies? \\
What epidemic disease \\
has been modeled? \\
Was models were applied \\
for forecasting an \\
epidemic peak? \\
\hline Purpose and hypothesis & What was the purpose of \\
& the study? \\
& Which part of the \\
epidemic process was \\
modeled (Peak time, peak \\
distance, number of the \\
peak, and duration of the \\
epidemic)? \\
What happened forecasts \\
earlier than any of these \\
parts?
\end{tabular}

Based on the Levac et al. enhancement model, some recommendations were presented in Table 2 for the clarifying stage 1 [17].

\section{Stage 2: Identifying eligible studies}

At this stage, the research strategy was described including a research basis, terminology, the period 
for research and the studies' language.

To achieve a comprehensive search strategy to identify the epidemic peak models, a large set of keywords were used in the search strategy (Table 3). The terms related to epidemic peak models were based on previous literature reviews and research team point of view. A systematic search of English literature from 2010 to August 2020 in PubMed was conducted to identify relevant studies. A summary of the research process was illustrated in Fig 1.

Table 2: Recommended items for identifying the research question based on the Levac et al. enhancement framework

\begin{tabular}{|l|l|}
\hline $\begin{array}{l}\text { Recommend } \\
\text { items }\end{array}$ & Description in the current study \\
\hline Concept & $\begin{array}{l}\text { Prediction methods in pick time } \\
\text { epidemic disease }\end{array}$ \\
\hline $\begin{array}{l}\text { Target } \\
\text { population }\end{array}$ & $\begin{array}{l}\text { All types of data were used in the } \\
\text { prediction methods in the studies. }\end{array}$ \\
\hline Purpose & $\begin{array}{l}\text { Identification of applied prediction } \\
\text { methods in pick time epidemic disease }\end{array}$ \\
\hline Output & A list of suggested recommendations. \\
\hline
\end{tabular}

Table 3: Set of keywords used in the search strategy

\begin{tabular}{|l|l|}
\hline Concept & Synonym \\
\hline Forecasting & $\begin{array}{l}\text { Estimate, Estimating, Predict, } \\
\text { Prediction, Model, Modeling, Risk, } \\
\text { Dynamics, and Approaches }\end{array}$ \\
\hline $\begin{array}{l}\text { Disease } \\
\text { Outbreaks }\end{array}$ & Epidemics \\
\hline Peak & Spread \\
\hline
\end{tabular}

\section{Stage 3: Selecting the eligible studies}

Inclusion criteria of the study were as follows:

- The studies were adopted on an epidemic peak prediction model for forecasting communicable diseases.

Exclusion criteria include studies from the following types:

- non-original

- review studies

- Studies that the describing theoretical concepts or proposing an epidemic peak prediction model.

- Specialist's commentaries and letters to the editorials.

Based on the inclusion and exclusion criteria, two researchers independently reviewed the title and abstract to identify studies according to the study objectives. The researchers kept a list of the reviewed studies that were excluded from the review along with the reasons for their exclusion.

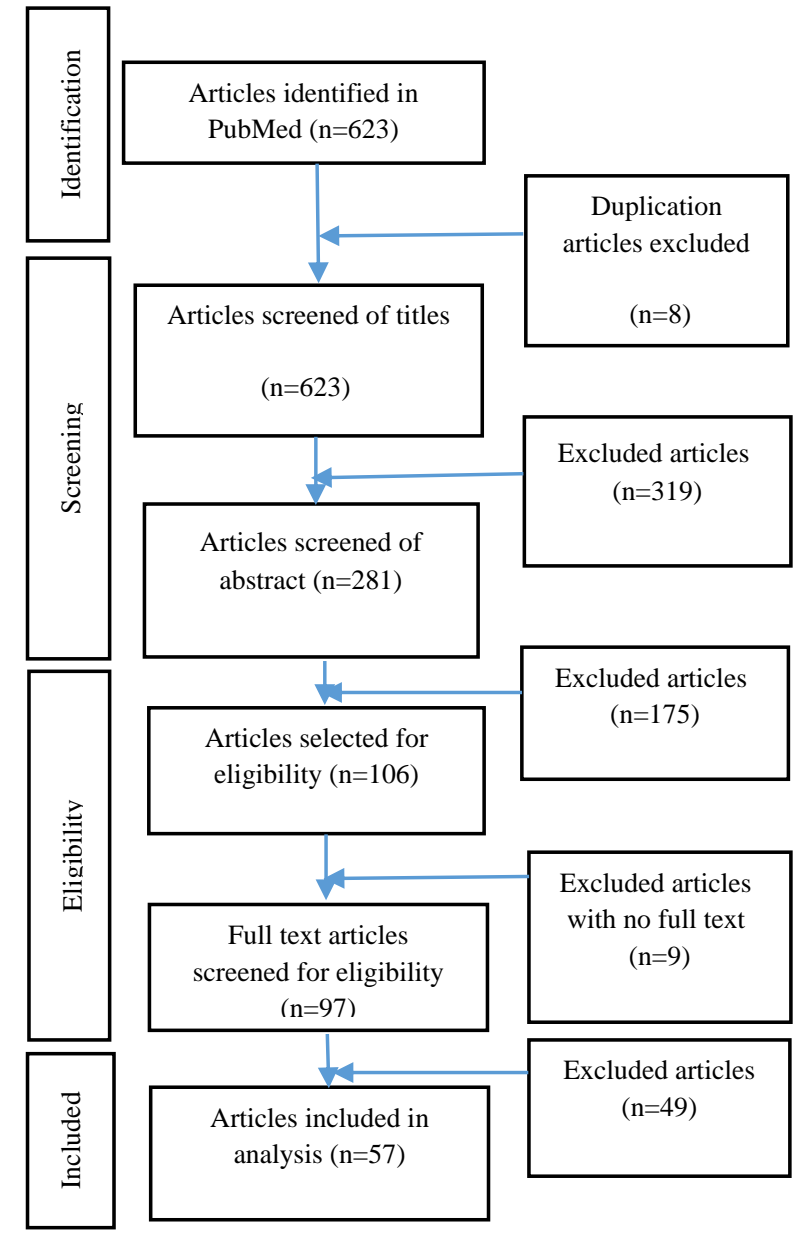

Fig 1: Articles review flow chart

The remaining studies were included in the data extraction process. Any disagreement to include a study was resolved by holding a discussion between the two evaluators. Unsolved disagreements were discussed with a third evaluator. The final decision was made after a consensus was reached between all three evaluators. Fig 2 shows a summary of stage 3 . Fig 2 drawn based on our previous research [18].

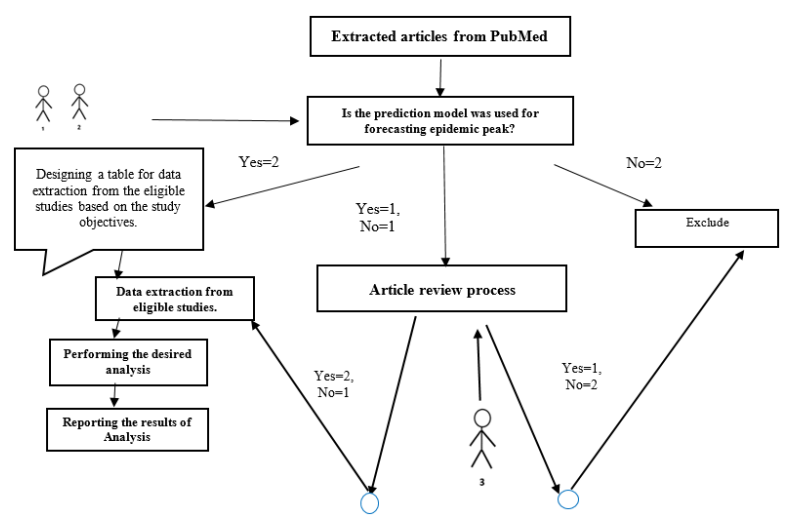

Fig 2: Summary of research process

\section{Stage 4: Charting the data}

In this stage, the suitable variables based on research questions were extracted from the eligible studies. In 
the pilot step, two reviewers independently extracted the variables from 10 eligible studies to develop a primary list of variables and a data extraction form. Then, two excel files were combined in expert panel meetings. In the second step, all eligible studies were assessed by researchers. As well, the data extraction form was updated during this step. In the third step, two data extraction forms were combined. The data were extracted. The categories were created based on frequency of extracted items. Unresolved disagreements were discussed with a third researcher in this stage.

A data extraction form was developed using Microsoft Excel 2010. Each row of the excel file represents an article and the columns represent the desired variables and the value of each row in the column [cell] contains the variable value. Identified variables were organized into four parts including general information, purpose and hypothesis, modeling, and model achievement (Table 4).

To ensure the proper variables categorization, the two validity and reliability indexes were applied to evaluate the categorization validity based on point of view of 5 field experts.

To assess reliability, in the pilot stage a sample of eligible studies $(n=10)$ was randomly selected. Two reviewers extracted the variables from the sample articles. The Kappa statistic was conducted to assess two reviewers' agreements to ensure that the reviewers have the same interpretation of the data and categories. A high agreement rate (kappa=84\%) was observed between two reviewers. Then, the extraction variables from all the eligible studies were started.

\section{Stage 5: Collecting, summarizing and reporting the results}

Both qualitative and quantitative methods were used to synthesize the extracted data categories study findings on prediction methods for epidemic diseases. Table frequency analysis, descriptive statistics, and qualitative thematic analysis were used for data analysis. As well, the results were reported either graphically or in the form of a table. The related findings to the study's purpose will be discussed and for future studies, some recommendations will be suggested.

\section{RESULTS}

In the present study all articles from 2010 to 2020 in PubMed database using our strategy search were extracted.

After filter 623 articles, 57 related articles were obtained. In continuous items such as type of method, peak time, peak distance, number of a peak, duration of the epidemic number will extract from eligible articles and will report.

Table 4: List of studied extracted data from eligible studies

\begin{tabular}{|c|c|c|}
\hline Aspect & Variables & Permitted value \\
\hline \multirow{5}{*}{$\begin{array}{l}\text { General } \\
\text { information }\end{array}$} & $\begin{array}{l}\text { Publication } \\
\text { year }\end{array}$ & $2010-2020$ \\
\hline & $\begin{array}{l}\text { Epidemic } \\
\text { disease }\end{array}$ & $\begin{array}{l}\text { Coronavirus, Ebola } \\
\text { and other } \\
\text { communicable } \\
\text { diseases. }\end{array}$ \\
\hline & $\begin{array}{l}\text { Author's } \\
\text { discipline }\end{array}$ & All discipline \\
\hline & $\begin{array}{l}\text { Proposing an } \\
\text { epidemic peak } \\
\text { model }\end{array}$ & Yes or no \\
\hline & Country & All countries \\
\hline \multirow{3}{*}{$\begin{array}{l}\text { Purpose and } \\
\text { hypothesis }\end{array}$} & $\begin{array}{l}\text { Forecasted } \\
\text { epidemic } \\
\text { process }\end{array}$ & $\begin{array}{l}\text { Peak time, peak } \\
\text { distance, number } \\
\text { of a peak, duration } \\
\text { of the epidemic } \\
\text { Number }\end{array}$ \\
\hline & $\begin{array}{l}\text { Occurrence } \\
\text { rate before } \\
\text { forecasted } \\
\text { peak time }\end{array}$ & Number \\
\hline & $\begin{array}{l}\text { Objective } \\
\text { study }\end{array}$ & $\begin{array}{l}\text { Improve public } \\
\text { health strategies }\end{array}$ \\
\hline \multirow{5}{*}{ Modeling } & Methods & $\begin{array}{l}\text { Time series, } \\
\text { scholastic model, } \\
\text { etc. }\end{array}$ \\
\hline & Input variables & Age, sex and so on \\
\hline & $\begin{array}{l}\text { Data } \\
\text { simulation }\end{array}$ & Yes and no \\
\hline & $\begin{array}{l}\text { Model } \\
\text { accuracy }\end{array}$ & $0 \%-100 \%$ \\
\hline & $\begin{array}{l}\text { Data analysis } \\
\text { software }\end{array}$ & $\begin{array}{l}\text { Mathlab, c++,c\#, } \\
\text { weka, and etc. }\end{array}$ \\
\hline \multirow{3}{*}{$\begin{array}{l}\text { Model } \\
\text { Achievement }\end{array}$} & Results & $\begin{array}{l}\text { Increase accuracy, } \\
\text { precision, etc. }\end{array}$ \\
\hline & $\begin{array}{l}\text { Population } \\
\text { characteristics }\end{array}$ & $\begin{array}{l}\text { For example, } \\
\text { number of } \\
\text { participants, and } \\
\text { their country, sex, } \\
\text { age, physician } \\
\text { specialty. }\end{array}$ \\
\hline & $\begin{array}{l}\text { Nature of } \\
\text { Healthcare } \\
\text { setting }\end{array}$ & $\begin{array}{l}\text { For example, } \\
\text { hospital, clinic, } \\
\text { primary care, } \\
\text { public or private } \\
\text { organization. }\end{array}$ \\
\hline
\end{tabular}

\section{DISCUSSION}

According to our knowledge, there are no review scopes related to epidemic peak prediction models. In this study, a protocol was conducted a scoping review for peak point prediction models for epidemic diseases using the Arksey framework [16] in combination with Levac [19] enhancement. A classify scheme was proposed for classification based on the frequency of values.

CONCLUSION 
The results of the analysis will help researchers by a summary of evidence to present new ideas and further research especially for studies were focused on COVID-19. Also our finding can help the epidemic disease management for future disease.

\section{ACKNOWLEDGEMENTS}

The present study is a part a research project supported by the Mashhad University of Medical Sciences (grant number 961731).

\section{AUTHOR'S CONTRIBUTION}

HT designed the study and managed the strategy searches and provided general guidance to the

\section{REFERENCES}

1. Centers for Disease Control and Prevention. Lesson 1: Introduction to epidemiology. In: Centers for Disease Control and Prevention. Principles of epidemiology in public health practice: An introduction to applied epidemiology and biostatistics. $3^{\text {rd }}$ ed. U.S. Department of Health and Human Services; 2006.

2. Myers MF, Rogers DJ, Cox J, Flahault A, Hay SI. Forecasting disease risk for increased epidemic preparedness in public health. Adv Parasitol. 2000; 47: 309-30. PMID: 10997211 DOI: 10.1016/s0065308x(00)47013-2 [PubMed]

3. Quinn SC, Kumar S. Health inequalities and infectious disease epidemics: A challenge for global health security. Biosecur Bioterror. 2014; 12(5): 263-73. PMID: 25254915 DOI: 10.1089/bsp.2014.0032 [PubMed]

4. Mcquilkin PA, Udhayashankar K, Niescierenko M, Maranda L. Health-care access during the ebola virus epidemic in Liberia. Am J Trop Med Hyg. 2017 Sep;97(3):931-6. PMID: 28722621 DOI: 10.4269/ajtmh.16-0702 [PubMed]

5. Rull M, Kickbusch I, Lauer H. Policy debate| international responses to global epidemics: Ebola and beyond. International Development Policy. 2015; 6(2): 1-33.

6. Riou J, Poletto C, Boëlle PY. Improving early epidemiological assessment of emerging aedestransmitted epidemics using historical data. PLoS Negl Trop Dis. 2018; 12(6): e0006526. PMID: 29864129 DOI: $10.1371 /$ journal.pntd.0006526 [PubMed]

7. Moss R, Zarebski A, Dawson P, McCaw JM. Forecasting influenza outbreak dynamics in melbourne from internet search query surveillance data. Influenza Other Respir Viruses. 2016; 10(4): 314-23. PMID: 26859411 DOI: 10.1111/irv.12376 [PubMed]

8. Tuite AR, Fisman DN. The idea model: A single equation approach to the ebola forecasting challenge. Epidemics. 2018; 22: 71-7. PMID: 27717616 DOI: 10.1016/j.epidem.2016.09.001 [PubMed] research team at all stage. EN and ZE filtered the searched articles. EN wrote the first draft of the manuscript of protocol article.

The authors agree on this final form of the manuscript, and attested that all authors contributed in the final draft of the manuscript.

\section{CONFLICTS OF INTEREST}

The authors declare no conflicts of interest regarding the publication of this study.

\section{FINANCIAL DISCLOSURE}

No financial interests related to the material of this manuscript have been declared.

9. Asher J. Forecasting ebola with a regression transmission model. Epidemics. 2018; 22: 50-5. PMID: 28342787 DOI: $10.1016 /$ j.epidem.2017.02.009 [PubMed]

10. Bioglio L, Génois M, Vestergaard CL, Poletto C, Barrat A, Colizza V. Recalibrating disease parameters for increasing realism in modeling epidemics in closed settings. BMC Infect Dis. 2016; 16(1): 676. PMID: 27842507 DOI: $10.1186 /$ s12879-016-2003-3 [PubMed]

11. Bolzoni L, Bonacini E, Soresina C, Groppi M. Timeoptimal control strategies in SIR epidemic models. Math Biosci. 2017; 292: 86-96. PMID: 28801246 DOI: 10.1016/j.mbs.2017.07.011 [PubMed]

12. Li J, Li W, Jin Z. The epidemic model based on the approximation for third-order motifs on networks. Math Biosci. 2018; 297: 12-26. PMID: 29330075 DOI: 10.1016/j.mbs.2018.01.002 [PubMed]

13. Ben-Nun M, Riley P, Turtle J, Bacon DP, Riley S. Forecasting national and regional influenza-like illness for the USA. PLoS Comput Biol. 2019; 15(5): e1007013. $\quad$ PMID: 31120881 DOI: 10.1371/journal.pcbi.1007013 [PubMed]

14. Zhang Y, Bambrick H, Mengersen K, Tong S, Feng L, Zhang L, et al. Resurgence of pertussis infections in Shandong, China: Space-time cluster and trend analysis. Am J Trop Med Hyg. 2019; 100(6): 1342-54. PMID: 30994096 DOI: 10.4269/ajtmh.19-0013 [PubMed]

15. Chowell G, Tariq A, Hyman JM. A novel sub-epidemic modeling framework for short-term forecasting epidemic waves. BMC Med. 2019; 17(1): 164. PMID: 31438953 DOI: $10.1186 / \mathrm{s} 12916-019-1406-6$ [PubMed]

16. Arksey H, O'Malley L. Scoping studies: Towards a methodological framework. International Journal of Social Research Methodology. 2005; 8(1): 19-32.

17. Colquhoun HL, Levac D, O'Brien KK, Straus S, Tricco AC, Perrier L, et al. Scoping reviews: Time for clarity in definition, methods, and reporting. J Clin Epidemiol. 2014; 67(12): 1291-4. PMID: 25034198 DOI: 10.1016/j.jclinepi.2014.03.013 [PubMed] 
18. Nazari E, Pour R, Tabesh H. Comprehensive overview of decision-fusion technique in healthcare: A scoping review protocol. Frontiers in Health Informatics. 2018; $7: 7$.
19. Levac D, Colquhoun H, O'Brien, K.K. Scoping studies: Advancing the methodology. Implementation Science. 2010; 5: 69. 